\title{
A Diachronic Study on Chinese Resultative Construction of Second Language Learners*
}

\author{
Yanmei Lu \\ Xinxiang Medical University, He Nan, China
}

\begin{abstract}
Resultative construction is a very special phenomenon in Chinese grammar and also a difficult issue for second language learners. This paper summarizes diachronic research on resultative construction including its definition, formation times, forming and development, the characteristic. As a comparative study of language, this paper can benefit the teaching and acquisition of Chinese resultative construction.
\end{abstract}

Index Terms - Chinese, resultative construction, diachronic

\section{INTRODUCTION}

For more than 30 years, Chinese resultative construction has been the focus of academic world because of its diversity in semantics and syntax. Based on different linguistic theories, scholars made intensive and deep researches on it and achieved certain research results. This paper summarizes the research results in a diachronic perspective and points out the problems and research prospect of this issue.

\section{The Definition And Formation Times of Resultative Construction}

It was Wang Li who first defined and made monographic study on Chinese resultative construction. He called it as "causative form". In 1980, Wang Li made the definition: "Causative form is a structure of word group. In form, transitive verb carries about adjective(修好, 弄坏) or transitive verbs carries about intransitive verbs (打死, 救活); In meaning, action and result are showed in one verbal word group. The action can make the object get certain result. So it is called causative form." Later, Wang Li revised the former definition and excluded intransitive verb plus intransitive verb and intransitive verb plus adjective. He said the first element must be transitive verb.

As for the formation times of resultative construction, experts didn't make a consensus on it. The representative views were as following:

1 Some scholars thought resultative construction came into being in Qin Dynasty, such as Zhou Chiming, Yu Jianping, Pan Yunzhong and Zhang Xiancheng. In 1957, Zhou Chiming said that "Sharing type of causative compound verb originated form the semantic relationship in Yin Dynasty. Departing form originated from syntactic relationship in Qin Dynasty." Also in this year, Yu Jianping put forward that resultative construction germinated in Zhou Dynasty, developed in Qin Dynasty and was used widely in Han Dynasty.

Scholars who thought resultative construction formed in Qin Dynasty ignored an important fact that intransitive and transitive verbs had different categories in ancient and modern Chinese. Different form modern Chinese, ancient Chinese didn't distinguish intransitive and transitive verbs clearly and many verbs could be used as intransitive and transitive at the same time. For instance, “灭”、“破”、“伤”、“断”could be used as transitive verbs in ancient Chinese. However, they were defined as intransitive verbs in modern Chinese. Therefore, “扑灭”、“攻破”、“射伤”in ancient Chinese could be seen as serial verbs or compound verbs. The viewpoint that resultative construction was formed in Qin Dynasty was doubtful.

2 Some scholars thought resultative construction appeared in Han Dynasty, such as Wang Li, Zhu Minche, Cheng Xiangqing, Song Shaonian and Wu Fuxiang. In 1958, Wang Li said that "resultative construction was appeared in Han Dynasty, expanded in the South and North Dynasty and used widely in Tang Dynasty." He used “推邽”、“击走”、“填 满” as the examples. Based on the semantic orientation of complements, Wu Fuxiang divided verb-complement into movement, agent and object, which appeared in Dong Han Dynasty, Song Dynasty and South and North Dynasty respectively. Among them, movement complement appeared first. Wang Li didn’t regard “扰乱”、“助长”、“拉杀”as resultative construction because they were specious. “扰乱”was bisyllable of synonymous morphemes. “助长” was a transitive form that omits a nominative, while “拉杀” was coordinate construction of two verbs.

3 In 1984, Janpanse scholar Zhi Cun Liang Zhi pointed out that in early middle Ages with a large increase in disyllables some words crossed the coordination usage and became compound verbs. Compound verbs probably appeared in Six Dynasty. He added that the formation of compound verb didn't finish in early middle Ages at a time.

\footnotetext{
* This paper and research are funded by the humanities and social sciences 2018 annual research project of Henan provincial department of education, the project number: 2018-ZZJH-429.
} 
The process was completed mostly in Tang Dynasty. The other scholars with the same viewpoints were Mei Zulin, Li Ping, Jiang Shaoyu and Liu Chenghui, etc.

4 According to Japanese sinologist, intransitive and transitive verbs were fixed as intransitive verbs in Tang Dynasty. So he thought compound verbs appeared no later than Tang Dynasty.

According to above discussion, on the one hand scholars carried on research on different materials. On the other hand, they had different understanding on the definition and formation times. They might come to different conclusions based on the same materials because of different viewpoints. Therefore, scholars remain far apart on the formation times of resultative construction. As the description in Modern Chinese (2007), the disagreement of grammar system comes from the different views of grammarian who acquired different materials, viewpoints and methods. To some degree, the grammar system was subjective.

\section{The Formation AND DeVelopment of Resultative Construction}

Resultative construction expressed action and semantic relations at the same time, which was a distinctive syntactic structure in Chinese. As the other language phenomenon, resultative construction didn't appear in ancient times. It experienced a development process. Resultative construction in ancient times was closely tied to serial verb construction which was the foundation of resultative construction. In order to study the formation and development of resultative construction, we had to research on the categories of resultative construction in ancient times.

Serial verb construction was the coordination of two or more than two verbs and appeared in the early ancient times. It could be divided into broad and narrow sense. The broad sense included two types: The first type had the same agentive subject. The verbs had their own objects which forms successive actions or events. The grammar structure was “ $\mathrm{V}_{1} \mathrm{O}_{1}+\mathrm{V}_{2} \mathrm{O}_{2}+\ldots . . \mathrm{VnOn}$ ”, such as “公惧, 队于车, 伤足, 丧屦” (Zuo Zhuan). The second form was two actions or events connected by the conjunction “而”. It could be divided into different categories based on different grammar and semantic features of the two verbs. Resultative construction in the narrow sense referred to the close connection of the verbs which could not be inserted any element. Its grammar form was $\mathrm{S}+\mathrm{V} 1+\mathrm{V} 2+\ldots \ldots+\mathrm{Vn}+(\mathrm{O})$. The number of the verbs could be two, three or four. Two forms were the most common. Without special annotation, we restricted the number into two. With the influence of two elements, serial verb construction in narrow sense appeared on the basis of broad resultative construction. On the one hand, Chinese polyphones appeared in ancient times which provide the necessary conditions for narrow resultative construction. On the other hand, in cognitive linguistics, syntactic structure was similar to the experience structure of human being. Chinese resultative construction was grammatical reflection of cognitive style, metaphor. It belonged to grammatical metaphor. In other words, the sequence of the two verbs in Chinese serial verb construction was determined by this cognitive style.

The serial verb construction (in narrow sense) was the syntactic foundation of resultative construction. Therefore, in order to find out the formation and development of various resultative constructions, we had to understand the syntax and characteristic of resultative construction in narrow sense. Resultative construction in narrow sense just provided syntactic preconditions for resultative construction. In semantic perspective, in some " $\mathrm{V}_{1}+\mathrm{V}_{2}$ "structures, $\mathrm{V}_{1}$ represented reason and $\mathrm{V}_{2}$ represented results which was very similar to resultative constructions. However, "grammatical analysis didn't depend on semantics only" (Jiang Shaoyu, 1999). The serial verb construction in narrow sense had essential differences with resultative construction. Resultative construction described causal relationship in one event while serial verb construction in narrow sense described causal relationship in two separated actions or events. All kinds of serial verb construction in narrow sense experienced different evolution and development since pre-Qin period and some didn't become resultative construction. However, they became attributive structure or coordination structure. This showed that whether serial verb construction could become resultative construction was decided by structure and semantics. Even if there were certain logic causal relationship between two actions in serial verb construction, they might not become resultative construction in the end.

\section{Motivation AND Mechanism of Resultative Construction Formation}

Some Chinese words developed from content words to function words, which was the result of grammaticalization. Grammaticalization was the term in Western linguistic field. While in Chinese traditional linguistics it was called "grammaticalization of content words". Grammaticalization emphasized the grammatical scope and the production of grammatical items. Shen Jiaxuan (1994) pointed out that "Grammaticalization referred to the process that content words in languages changed into functional words with grammatical functions." He noted further that grammaticalization was the process in which content words changed into grammatical marker. Liu Jian, Cao Guangshun and Wu Fuxiang (1995) said that normally one content word changed its meaning because of the change of syntactic position or combination function. Furthermore, the meaning changes caused the change of syntactic position or combination function. Finally, the word lost the original meaning and had certain grammatical meaning, which was called functional words. This process was called grammaticalization. Concerning the explanation of grammaticalization in academic world, Hopper \& Traught's view was representative. In their opinion, there are two aspects of grammaticalization research. Diachronically, researchers investigated the origin of the grammatical items, especially the process of their development. In the study, it concerned how a common word changed into grammatical marker and the further development of the 
grammatical marker. Synchronically, grammaticalization was regarded as a kind of syntactic chapter and pragmatic phenomenon which focused on the various forms of languages.

Grammaticalized result complement in resultative construction was called complementary components which were caused by the grammaticalization of verb-complement structure. Although resultative construction had different origins, they had the same formation mechanism and grammaticalization causes. In syntactic meaning, the complements and verbs must be close neighbors frequently, which was the syntactic condition. As for rhythm forms, verbs and complements became disyllables and their structure would be changed. After reanalysis, they formed a highly integrated structure, resultative construction. Based on the grammaticalization of resultative construction, the complement of resultative construction could be grammaticalized to complementary components " $R_{2}$ ", even " $R_{3}$ ". In cognitive perspective, there were expressions from “摔死了” to “神气死了”, from “墙敲坏了” to “孩子宠坏了”, from “鞋底磨 破了” to “真相被揭穿了”. The change from concreteness to abstraction, from physiology to psychology, from space to time was one way of human cognition. This connection was the association of objective things in human cognition, which was set up by metaphors. Then, we would analyze the formation mechanisms of resultative construction from syntactic aspect, disyllable tendency and analogy effect. We would also explain grammaticalization causes from metaphor and metonymy.

\section{A. Syntactic and Semantic Factors}

Changes of syntactic position and semantic meaning played important roles in the formation of resultative construction. In 1987, Jie Huiquan explained the fixation of syntactic position. A content word changed into a functional word expressing certain grammatical relationship because it often appeared in certain position expressing a proper grammatical relationship. In 1995, Liu Jian discussed the grammaticalization of Chinese words from the aspect of syntactic position change, semantic meaning change, context influence and reanalysis. In 1998, Hongbo pointed out that grammaticalization of Chinese content words had two kinds. They were cognitive effect and syntactic semantics. Among them, syntactic semantics was the main mechanism. The grammaticalization of most content words in Chinese was influenced by syntactic structure and syntactic semantics.

Usually, only one verb used as the predicate in an expression, which was the center of the sentence structure. If two words formed serial verb construction and they were close neighbors frequently, they would complete with each other and had differentiation between priority and others. If the word was secondary in the serial verb construction, it would be weakened. If a verb played a secondary role in a sentence and its position was fixed in a sentence, its meaning was grammaticalized gradually and its grammatical function was changed at the same time. Once the resultative construction was formed, the latter verb was no longer a predicate but the complementary component of the predicate verb which was called complement.

The Chinese words “成、穿、掉、坏、破、死、透、着” changed from verbs to complementary components, which started from the serial verb construction. The grammaticalization of them could be summarized as this: from serial verb construction to resultative construction ( $\mathrm{R}_{1}$ expressing the verb result) to resultative construction (complementary component $\mathrm{R}_{2}$ ). Some could even be grammaticalized as mark $\mathrm{R}_{3}$. In this grammaticalization chain, the change of syntactic position and entering into certain grammatical structure (serial verb construction) were the cause and foundation of the change. Only in certain grammatical position and under the influence of all kinds of factors, the words could produce new usage, which used as complement after main verbs. In conclusion, the change of syntactic position was very important towards the formation of resultative construction.

\section{B. Diphonic Tendency}

Bisyllablization played a decisive role in Chinese development history. In 1988, Wang Li regarded bisyllablization as one of the five important changes in Chinese grammar history. In 2002, Shi Liuzhi put forward that the formation of verb-complement construction was the actually the fusion of the verb and result component. There were many fusion factors, in which bisyllablization was essential. Bisyllablization had profound influence on the word formation, morphology and syntax.

As for bisyllablization, it referred to that the word changed from monosyllable to bisyllable in Chinese development. With the further research on Chinese grammaticalization, experts had deeper understanding towards it. In 2002, Shi Liuzhi thought that two monosyllables which were close neighbors frequently might become a bisyllable under the influence of bisyllablization. The process was called compounding in which two morphemes weakened or lose the word boundary and became one language unit. According to Wu Weishan's view in 2003, bisyllablization referred to that two monosyllables formed the basic rhythmic unit, merter. With the influence of rhythmic unit, two monosyllables which were close neighbors frequently might compound into one language unit. The compound condition was the two monosyllables which co-occured frequently.

\section{Analogy Effect}

In 1993, Hopper and Traugott pointed out that analogy was the paradigm of grammar organizations which would cause the change of surface collocation. The production, development and wide use of verb-complement structure were caused by syntactic semantics, bisyllablization and analogy.

In ancient Chinese, because $\mathrm{V}_{\mathrm{t} 2}$ became intransitive and the transitive usage of $\mathrm{V}_{\mathrm{i}-\mathrm{t}}$ was declined, some serial verb 
construction “ $\mathrm{V}_{\mathrm{t} 1}+\mathrm{V}_{\mathrm{t} 2}+\mathrm{O}$ ” and “ $\mathrm{V}_{\mathrm{t}}+\mathrm{V}_{\mathrm{i}-\mathrm{t}}+\mathrm{O}$ ” fused into resultative construction “ $\mathrm{V}+\mathrm{R}+\mathrm{O}$ ”, such as “ $\mathrm{V}$ 得”、“ $\mathrm{V}$ 取”、“ $\mathrm{V}$ 破” and “V 坏”. This new syntactic construction became a motive power which made action verb $\mathrm{V}_{1}$ and result verb $\mathrm{V}_{2}$ combine and became resultative construction. According to the view of Wei Zhaohui in 2008, analogy was one of the important factors to induce changes. In other words, it was the generalization of grammatical rules. Because of analogy, many $\mathrm{V}_{\mathrm{t} 2}$ in serial verb construction became intransitive verb and complement of former verb, such as " $\mathrm{V}$ 掉” and " $\mathrm{V}$ 住". As the causative usage declined, the secondary verb " $\mathrm{V}_{\mathrm{i}-\mathrm{t}}$ " in serial verb construction " $\mathrm{V}_{\mathrm{t}}+\mathrm{V}_{\mathrm{i}-\mathrm{t}}+\mathrm{O}$ " regained the intransitive usage and didn't govern object alone. It combined with the former verb and became resultative construction, such as "V 穿” and "V 动”.

\section{Cognitive Motivation}

In the last decade, grammaticalization has been the major scope of cognitive linguistics. In 1987, Lakeoff proposed the idealized cognitive model (ICM) in the research of semantic scope and concept structure of natural language. Based on different construction principles, ICM could be divided to four types: proposition model, image schema model, metaphor model and metonymy model. Metaphor model and metonymy model played important roles in the grammaticalization of resultative construction.

The basic cognitive style of human being started from specific to general, from space domain to time domain and went to subtler domain. That is to say, when people understood things, they usually started from themselves and the things around them, then extended to external things such as space, time and characteristics. The projection between the different cognitive scopes was accomplished by metaphor. Metaphor was a common cognitive phenomenon and language expression phenomenon. In 1980, Lakeoff regarded metaphor as a systematic method of human's thinking, action and expression, which was called metaphorical concept of conceptual metaphor. In daily life, people often understood, thought, experienced invisible and undefinable concept in accordance with familiar, visible and specific concept. With the development of human cognition, metaphorical thinking ability became a creative thinking ability which was the high phase of cognitive development and an essential cognitive ability towards abstract things. This abstract cognitive ability originated from the understanding of the similarities between two concepts.

During the diachronic evolution of resultative construction, the effect of metaphor could be seen in the complement grammaticalization. For instance, the semantic evolution of "V 破" was connected with human cognitive activity and metaphors. For the daily language “衣服穿破了”, “鞋子磨破了” and “手指划破了”, we discovered that clothes, shoes and fingers which were intact became incomplete because of damage. The physical feeling of something or somebody from intact to incomplete was similar to the psychological feeling of abstract things from intact to incomplete. There were examples “一语道破真相”、“盗窃案侦破了” and “阴谋已被揭破”. The truth, theft case and conspiracy were intact. Once they were revealed, they were broken and incomplete like the things. In phrases “打破成见”, “突破常规思 路” and “冲破传统思想”, “成见”, “常规思路” and “传统思想” were subjective concepts which were considered intact and became incomplete after breakthrough.

Traditionally, metonymy was also regarded as a kind of rhetoric device. Cognitive linguists thought metonymy was not the substitution of words but an import method of understanding things. An object, a thing and a concept had a lot of characteristics. However, people's cognition was only focused on the most prominent, memorable and understandable characteristics which were called highlight attributes. Metonymy was the connection between different cognitive domains. In metonymy, a prominent thing replaced another thing, parts replacing the whole or container replacing the function. For instance, “银发游” represented tourist groups of old people. “白宫” represented American government. “国脚” represented excellent football players and “新面孔” represented someone new.

In a diachronic study on resultative construction "V 好", we discovered that metonymy played a role in the semantic evolution of “好”. “好” was a Chinese associative compound composed of “女” and “子” which were pictographic characters. Xu Shen in Xi Han Dynasty explained it in Shuo Wen Jie Zi as “好，美也，从女子。” It meant that “好” represented beauty of women. According to Duan Yucai, “好”represented the beauty of women at first and then it referred to all the beautiful things. It was metonymy from parts to the whole as “好” changed from the beauty of women to the beauty of all things. In 2008, Chen Mei thought that “好” with different semantics had related meaning but different word formation, which highlighted the different aspects of things. The verb “好” highlighted actions and habits while the adjective “好” highlighted nature and state. The change between different word formations was the result of metonymy. Metonymy established connection between similar and related cognitive domain. It was also the transition of the related cognitive domains. Metonymy played an important role in the semantic evolution of “好”.

\section{The Characteristics OF Resultative CONSTRUCTION}

Lv Shuxiang illustrated resultative construction in his book Eighty Hundred Words (1980) in Modern Chinese as this: resultative construction was formed by main verbs plus adjectives verbs which shows results. The adjectives and verbs had some common words, such as “了、着、住、掉、走、动、完、好、成”etc.

As described by Zhu Dexi(1982), predicate-complement structure which was formed by result complements 
belonged to agglutinating-style structure. The complement included adjectives and verbs, such as “长大、变小、 染红”or “写成、杀死、说完”. The form group was adjectives and the latter one was verbs. In addition, he pointed out that some verbs could be used as result complement, such as “走、跑、动、倒、翻、病、死、见、懂、透”.

In the article Formation Times of Chinese Resultative Construction, Jiang Shaoyu said that resultative construction should emphasize the definition in semantics rather than its semantics. There were two conditions for resultative constructions. First, the second verbs in serial verbs was automated or blurred. Second, automation didn't have causative usage and didn't form predicate and object structure with the objects. In 2004, Liu Ziyu thought that objects were not the necessary conditions for resultative construction after Tang Dynasty.

\section{CONCLUSION}

Resultative construction has been the focus in grammar field for many scholars since 1980s. There are many influential works in recent 20 years. As an agglutinating complement, resultative construction was very characteristic and had high value for research. In a diachronic perspective, minor sentences in pre-Qin Dynasty, the double predicate sentences and resultative constructions which appeared in ancient times had the evolution from chapters to syntax and morphology. Resultative construction was the result of compound predicate and had the tendency of lexicalization. Despite the large number of achievements, there were still some problems worth researching. First, we could perfect the research in macro-perspective. Second, as a kind of construction, we could make deep research on many specific phenomena in order to make more sensible interpretation.

\section{REFERENCES}

[1] Jiang Shaoyu. (1994). The generating times of resultative construction. Beijing: Beijing University Press.

[2] Liu Shizhen. (1992). Historical grammar in the South and North Dynasty. Nanjing: Nanjing University Press.

[3] Lv Shuxiang. (1979). Analyzing Chinese grammar. Beijing: The Commercial Press.

[4] Lv Shuxiang. (2010). Eight hundred words in modern Chinese. Beijing: The Commercial Press.

[5] Mie Zulin. (1991). The Development of Verb-Complement Construction Based on “动、杀” and “动、死” in Han Dynasty. Bundle theory of linguistics, 16, 112-136.

[6] Taitian Chenfu. (1987). Historical Grammar of Chinese Language. Beijing: Beijing University Press.

[7] Wang Li. (1980). A historical study on Chinese language. Beijing: China Publishing House.

[8] Wu Fuxiang. (1999). The origin of modern verb-complement construction. Beijing: China Social Sciences Press.

[9] Yu Jianping. (1959). The origin and development of causative form. Beijing: China Publishing House.

[10] Zhao Changcai. (2000). A diachronic study on Chinese resultative construction. Ph.D. dissertation, Graduate school of Chinese academy of social sciences.

[11] Zhicun Liangzhi. (1984). A research of Chinese grammar history. Beijing: China Publishing House.

Yanmei Lu was born in Jiyuan, China in 1982. She received her MA degree in language and literature from Henan University, China in 2010.

She is currently a lecturer in the School of Foreign Languages, Xinxiang Medical University, Xinxiang, China. Her research interests include linguistics and applied linguistics. 